\title{
TECNOLOGIA SOCIAL PARA ABASTECIMENTO DE ÁGUA DE COMUNIDADES RIBEIRINHAS NA REGIÃO DO MÉDIO SOLIMÕES (AMAZONAS)
}

\section{SOCIAL TECHNOLOGY FOR WATER SUPLLY TO RIVERINE COMMUNITIES IN THE MEDIUM SOLIMÕES RIVER REGION (AMAZONAS)}

\author{
Maria Cecilia Rosinski Lima Gomes ${ }^{(1)}$ \\ Pesquisadora, Corrdenadora do Programa Qualidade de Vida do Instituto de Desenvolvimento Sustentável Mamirauá - \\ IDSM \\ Rafaela Dias Lopes ${ }^{(2)}$ \\ Analista de Tecnologias Sociais - IDSM \\ Ademil Vilena $\operatorname{Reis}^{(3)}$ \\ Técnico de Tecnologias Sociais - IDSM \\ Maria das Mercês Bezerra da Silva ${ }^{(4)}$ \\ Técnica de saúde - IDSM \\ Maria das Dores Marinho Gomes ${ }^{(5)}$ \\ Técnica de Saúde - IDSM \\ Dávila Suelen Souza Corrêa ${ }^{(6)}$ \\ Diretora de Manejo e Desenvolvimento - IDSM \\ engceciliagomes@gmai.coml ${ }^{(1)}$

\section{RESUMO} \\ As dificuldades de acesso a água nem sempre estão relacionadas com a escassez hídrica. No Amazonas, principalmente \\ em áreas rurais, uma grande parcela da população sofre com a falta de água em quantidade e qualidade adequada para \\ atender às demandas domésticas diárias básicas, mesmo estando cercada por rios. Tendo em vista as especificidades \\ regionais do Estado, existe a necessidade de se projetar tecnologias que considerem a realidade local. Assim, visando a \\ melhoria na qualidade de vida da população ribeirinha residente em áreas de várzea, foi elaborado e instalado em \\ comunidades amazônicas um sistema de bombeamento e abastecimento de água alimentado por energia solar
}

\begin{abstract}
The difficulties of water access are not always related to water scarcity. In the Amazon, mainly in rural areas, a large number of population suffers because a lack of water, in appropriate quantity and quality, to comply with basic domestic demands, even in places fed by rivers. In view of the regional specificities of the State, there is a need to design technologies that consider the local reality. Thus, to improve the riverine population quality of life, specifically those who lives in floodplain areas, named "várzea", a pumping and water supply system powered by solar energy was designed and installed in Amazonian communities.
\end{abstract}

Palavras-chave: 1. Tecnologia social 2. População ribeirinha 3. Abastecimento de água 4. Várzea 5. Energia solar fotovoltaica.

Key words: 1. Social Technology 2. Riverine population 3. Water Supply 4. Varzea 5. Photovoltaics.

\section{INTRODUÇÃ̃O}

O estado do Amazonas possui uma vasta extensão de corpos hídricos superficiais, o que, contudo, não reflete na qualidade da água consumida por uma grande parcela da população. Apesar de a Organização das Nações Unidas (ONU) reconhecer o direito a água em quantidade e qualidade adequada às necessidades básicas da população, segundo o Instituto Brasileiro de Geografia e Estatística (IBGE, 2014), 90\% dos domicílios do Amazonas não é atendida por rede geral de 
abastecimento de água, ou seja, não possui água encanada dentro de casa. Essa situação se agrava devido à diversidade geográfica e cultural da região, o que acarreta na necessidade de diferentes soluções sanitárias. As comunidades situadas em regiões de várzea, por exemplo, são impactadas pela inundação anual, a qual ocorre devido a variação periódica do nível de água dos rios e lagos. Dessa forma, a população que mora em casas de palafita nesses locais, enfrenta continuamente duas realidades, no período das cheias a água dos rios encontra-se próximas de suas casas. Já na seca, as comunidades podem ficar distantes do ponto de captação de água, tanto em extensão quando em elevação, sendo necessário atravessar praias, lamaçais ou subidas íngremes sem escadas adequadas. Assim sendo, normalmente atividades domésticas, como limpeza de louça e roupa, são realizadas diretamente na beira do rio, acarretando em longos períodos de exposição ao som, já a água para consumo é transportada para casa em baldes. Além disso, grande parte das pessoas aproveitam água de chuva para realizar todas as atividades ou somente para o consumo. Segundo estudo realizado na região do Médio Solimões por Pacifico et al. (2021), onde não há abastecimento de água, são provenientes da chuva $83 \%$ da água de beber e 33\% da água de cozinhar. Como o período de maior dificuldade para acessar a água, quando os rios estão mais secos, é também quando ocorre a menor quantidade de chuvas, parte da população encontra dificuldade, devido à falta de estrutura, em armazenar água de chuva suficiente para atender a todas as necessidades domésticas. O trabalho tem por principal objetivo atender comunidades de várzea que não tem acesso à água encanada, melhorando as condições de acesso para uso doméstico.

\section{HISTÓRICO}

A falta de acesso à água de qualidade em comunidades amazônicas é uma realidade vivida na região ao longo de anos. A situação é amenizada devido a prática das populações tradicionais de habitarem as margens dos rios, ou próximos a igarapés e nascentes de água, o que facilita as atividades domesticas diárias e o deslocamento dessas populações, feitos normalmente por canoas ao longo do rio. Na tentativa de encontrar soluções para melhorar o acesso e conscientizar sobre o uso da água, algumas instituições e coletivos fizeram tentativas de inovação, tais como o Movimento de Educação de Base (MEB), a Prelazia de Tefé, o Memorial Chico Mendes e o Instituto de Desenvolvimento Sustentável (IDSM). O IDSM atua na região do Médio Solimões desde meados dos anos 90 com iniciativas de educação popular, tecnologias sociais, dentre outras atividades de pesquisa e desenvolvimento. No que se refere ao acesso à água, o IDSM já atuou com perfuração de poços artesianos, instalação de unidades de aproveitamento de água de chuva e atividades de orientação quanto ao uso da água e cuidados com a saúde, tais como, uso de cloro e filtro doméstico, higiene das mãos, uso de sanitários, etc.

Os primeiros experimentos de bombeamento de água foram iniciados em 1995, usando bombas manuais para água subterrânea (GOMES et al., 2019). As primeiras instalações do Sistema de Abastecimento de Água com energia solar foram realizadas em 2001 e até o presente momento 21 unidades foram instaladas, porém diversas foram desativadas, por diferentes motivos. Apesar de essa tecnologia ser elaborada para atender algumas especificidades das comunidades de várzea, é uma solução que pode ser utilizada em outras áreas que necessitem de realizar captação e bombeamento de água. Contudo, vale ressaltar que a organização comunitária e participação de instituições governamentais na gestão do sistema é de extrema necessidade para aumentar sua vida útil do mesmo e garantir seu funcionamento adequado.

\section{METODOLOGIA}

O Sistema de Abastecimento de Água (SAA) descrito neste trabalho utiliza da captação de água de chuva com geração de energia solar. Considerando que grande parte das comunidades atendidas não possuem rede de energia elétrica, tendo como fonte de energia motores movidos por combustível 

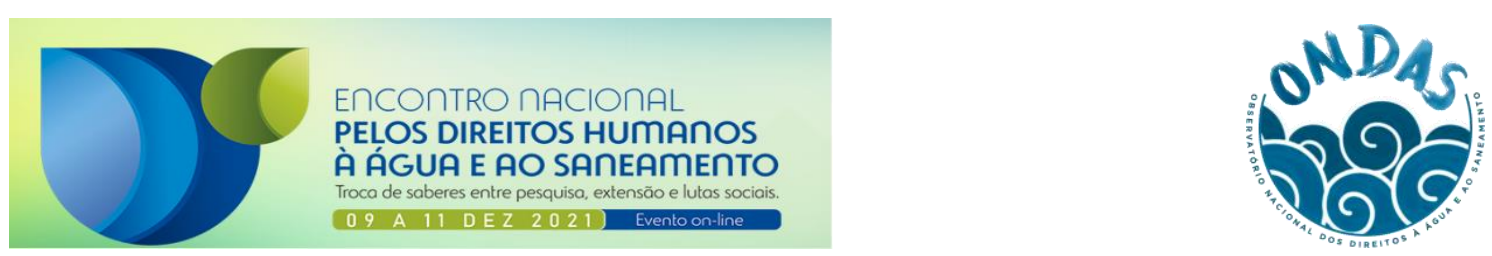

fóssil, a energia solar fotovoltaica foi pensada como alternativa sustentável, no sentido econômico e ambiental. As placas solares são colocadas em estruturas flutuantes que podem ser movidas de acordo com a sazonalidade hídrica. Para reduzir o custo com manutenção e aumentar a vida útil do sistema, não são utilizadas baterias para armazenamento de energia, portanto, o bombeamento ocorre durante o dia, quando as placas fotovoltaicas são alimentadas pela energia solar.

Figura 1: Instalação das placas solares em estrutura flutuante

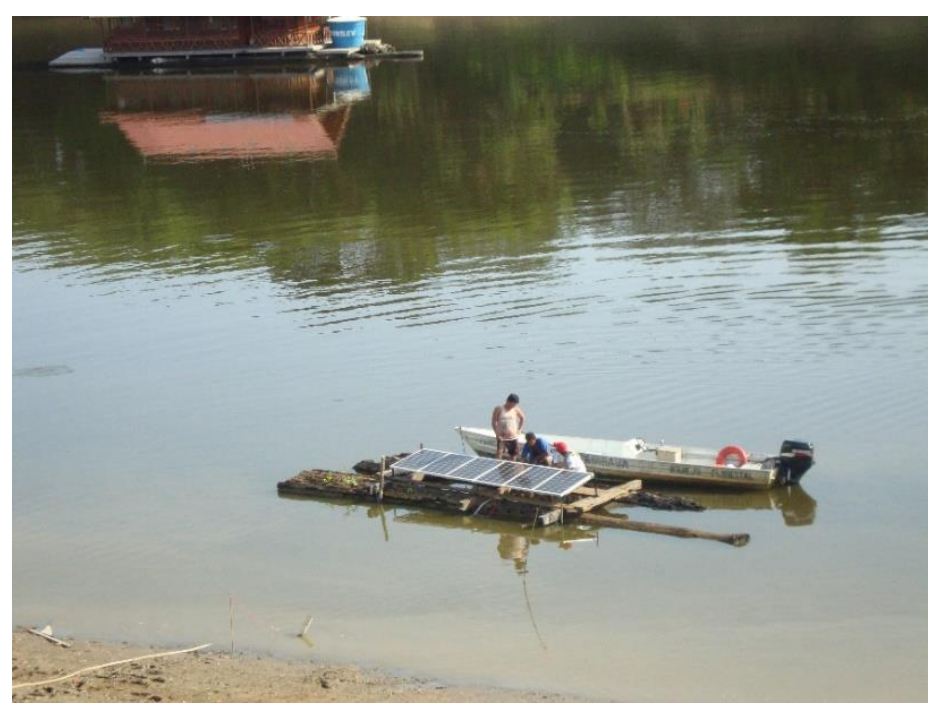

Fonte: Ademir Reis

O bombeamento então é feito para um reservatório central, o qual é sustentado por estrutura de madeira, material retirado da região. A água passa por um pré-tratamento de filtração que visa remover sólidos grosseiros. Finalmente, a distribuição via canalização atende todas as residências com um ponto de água interno.

Para execução do projeto o instituto conta com a participação da população e dos gestores públicos, objetivando uma gestão compartilhada do sistema. Dessa forma, as comunidades, ao participar da construção, principalmente nas atividades de retirada da madeira e escavação das valas para passagem da tubulação, se aproximam da tecnologia instalada, o que ajuda na compreensão e apropriação do sistema.

Figura 2: Participação dos moradores na instalação do sistema

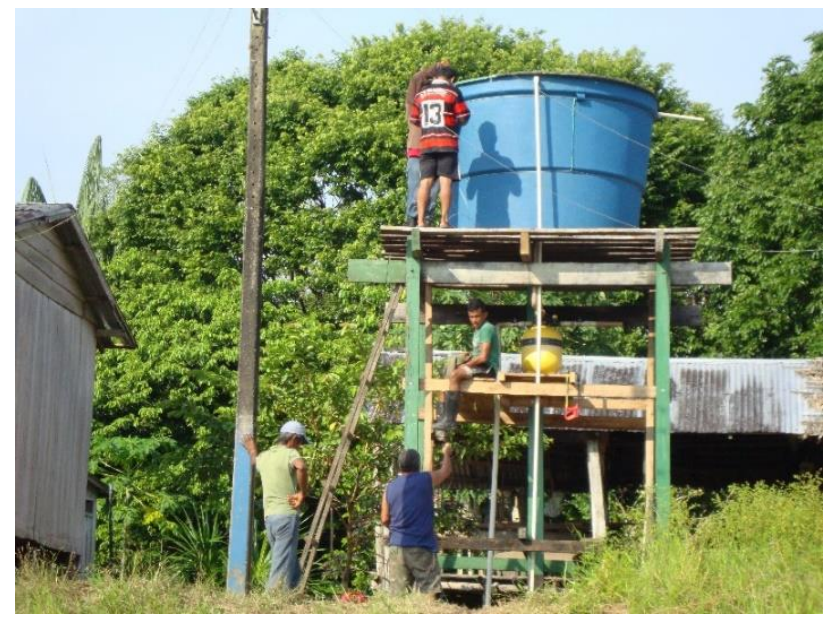

Fonte: Ademir Reis 
Contudo, tendo em vista que o abastecimento de água é de responsabilidade governamental, sendo um dos componentes do saneamento básico previsto pela Lei no11.445/2007, IDSM atua de forma a não isentar tais entidades de suas responsabilidades. As prefeituras municipais e outras instituições interessadas são convidadas, através de um acordo de gestão, a participar ativamente da instalação e manutenção das estruturas instaladas, juntamente com os comunitários atendidos.

\section{RESULTADOS ALCANÇADOS}

As comunidades ribeirinhas até então atendidas pelo IDSM com o Sistemas de Abastecimento de Água com energia solar são banhadas por rios que apresentam grande quantidade de sólidos em suspensão e/ou muita matéria orgânica dissolvida o que dificulta o tratamento, portanto, o sistema de filtros inserido para o tratamento não é suficiente para atender aos padrões de potabilidade da água para consumo. Existe, por parte de oficinas realizadas pelo IDSM e também por atuação dos agentes comunitários de saúde presentes na região, a realização de um trabalho de capacitação e conscientização quanto ao uso do cloro no tratamento doméstico da água. Entretanto, essa ainda não é uma prática adequadamente realizada. Apesar de as estruturas instaladas não atenderem a população com água potável, a qualidade de vida dos moradores é impactada no que se refere ao acesso à água em quantidade adequada para realizar as atividades domésticas sem necessidade de se deslocar até os corpos hídricos. Esse impacto pode ser observado na fala de alguns moradores, quando perguntados sobre os impactos gerados com a instalação do sistema:

“Antes tomava banho na beira, agora toma em terra, era ruim deixar os meninos pequenos em casa só". (Tania Maria S. Jarauá);

“Deixar de pegar água na beira e se livrar dos ataques dos jacarés”. (Sara Cavalcante, Jarauá);

"Não precisar ir à beira, melhorar a saúde e ter água boa, diminuir os riscos das crianças caírem no rio". (Paulo Flavio Feitosa, Vila Nova Amanã)

"Parar de todo dia ir à beira do rio fazer as coisas de casa, parar de pegar sol e carregar vasilhas, subir e descer com peso". (Oreane de Oliveira, Porto Braga)

Em estudo sobre as respostas sociais ao SAA, Moura (2007) observou um maior impacto no cotidiano de idosos, pela possibilidade de tomar banho dentro do domicílio e de mulheres e crianças, pois são elas as principais responsáveis pelas atividades domésticas, além de terem maior segurança ao fazer uso da água no período noturno. Pacifico et al. (2021) ao fazer a análise dos impactos gerados nas populações beneficiadas pelo SAA observou que houve uma mudança no tempo gasto com atividades domésticas diárias, realizadas principalmente por mulheres e crianças. Segundos as autoras, o acesso a água encanada também refletiu na aquisição de itens que melhoram a infraestrutura e qualidade do trabalho doméstico, foi possível observar que $24,2 \%$ das famílias acompanhadas pelo estudo adquiriram máquina de lavar roupa e $27,2 \%$ passaram a ter caixa d'água em seus domínios. Além da redução do esforço de trabalho e do tempo de exposição ao sol, foi contatado também alterações nos hábitos higiênico sanitários de parte dos moradores, que fizeram investimento em local para tomar banho, fazer as necessidades e lavar as mãos, essas instalações foram feitas em cerca de $10 \%$ dos domicílios estudados.

\section{CONCLUSÕES}

Promover o direito a água é oferecer melhoria para a saúde familiar, não somente no que se refere à redução de contaminações, mas também na redução do esforço físico, da exposição ao sol e a animais como jacarés e cobras. Esse direito, garantido em lei, demanda a implantação de estruturas que sejam condizentes com a realidade do ambiente. Ademais, mesmo uma estrutura planejada para que possa ter baixo custo de funcionamento, sem demanda de insumos básicos para o funcionamento, como 
combustível ou produtos químicos, necessita de um cuidado com manutenção e gestão. Portanto, a promoção de parcerias entre instituições de pesquisa e governamentais são um caminho para que as comunidades tenham acesso contínuo à água de qualidade, ficando menos expostos às sazonalidades ambientais que os circundam. A instalação de Sistemas de Abastecimento de Água com energia solar permitem a melhoria da qualidade de vida principalmente de mulheres, idosos e crianças e é uma dentre muitas medidas importantes de serem adotadas em comunidades que ainda não possuem água encanada em suas casas.

\section{REFERÊNCIAS}

GOMES, M C.; NASCIMENTO, A. C. S. de; CORRÊA, D. S. de S.; BRITO, O. S.; h, E. A. F. Surrounded by sun and water: development of a water supply system for riverine peoples in Amazonia. Revista Tecnologia e Sociedade, v. 15, n. 35, p. 92-112, 2019.

IBGE - Instituto Brasileiro de Geografia e Estatística. Censo Demográfico 2010: características da população e dos domicílios - resultados do universo. Rio de Janeiro: Instituto Brasileiro de Geografia e Estatística; 2011

MINISTÉRIO DA SAÚDE. Portaria de Consolidação N. 5, de 28 de setembro de 2017. Consolidação das normas sobre as ações e os serviços de saúde do Sistema Único de Saúde. Diário Oficial da União 2017; 29 set.

MOURA, A. F. M. Água de beber, água de cozinhar, água de tomar banho: diversidade socioambiental no consumo da água pelos moradores da várzea de Mamirauá, Estado do Amazonas. Cadernos Saúde Coletiva, Rio de Janeiro, 15(4), p. 501-516. 2007.

PACIFICO, A. N.; NASCIMENTO, A. C. S. de; CORREAA, D. S. S.; PENTEADO, I. M.; BORGES PEDRO, J. P.; GOMES, M. C. R. L.; GOMES, U. A. F. Tecnologia para acesso à água na várzea amazônica: impactos positivos na vida de comunidades ribeirinhas do Médio Solimões, Amazonas.

Cadernos de Saúde Pública, 37 (3), p.1-10. 2021. 